\title{
Prevalence Of Breast Cancer Among High Risk Women In Selected Rural Areas At Puducherry.
}

\author{
*Prof.AnnieAnnal.M, ${ }^{* *}$ S.Lavanya, ${ }^{* * *}$ Uma Maheswar.R\& ${ }^{* * * *}$ Anitha.B.
}

\begin{abstract}
:
Breast cancer is the leading cause of cancer among women regardless of race and ethnicity. Worldwide 10 million new cases of invasive cancer are diagnosed each year. 10\% arise in the breast, which makes it the second most common site of malignant neoplasm after lung (WHO 2001). In India, for the year 2012, about 144,937 women were newly detected with breast cancer and 70,218 women died of breast cancer. The burden of breast cancer in India (18.5\%) is increasing. The peak occurrence in developed countries are above the age of 50 whereas in India it is above the age of 40. Descriptive research design was adopted for this study. The population of the study was Women in the age between 40 -60 yrs, residing seliamedu village Puducherry. 7 women with high risk factors of Breast Cancer were undergone Mammogram to confirm the diagnosis of Breast cancer. The data were analyzed through descriptive statistics. The present study revealed that among 200 women, seven women were suspected with high risk factors and out of that seven, two women were diagnosed as breast cancer with the help of Mammogram-the confirmatory diagnostic measure.
\end{abstract}

\section{Key words: Breast Cancer, Mammogram}

\section{INTRODUCTION}

Increased incidence of cancer in recent years and its impact on different physical, mental, and social dimensions of human life have turned it to a major problem of the century ${ }^{1}$. The incidence of this disease in developed countries varies from 1 to 2 percent, with almost 5\% yearly increase in less developed countries 2.According to estimates, more than 7 million people globally die from cancer. It is predicted that the number of new cancerous cases rises from 10 to 15 million by 2020 3,4. Meanwhile, breast cancer is the most prevalent type of malignant neoplasms among women ${ }^{5}$. Breast cancer is the most common type of cancer among women in the US with the incidence rate of $12.5 \%$. The risk of an individual dying from breast cancer is 1-in-35 6 .

The burden of breast cancer is increasing in both developed and developing countries; the peak occurrence of breast cancer in developed countries is above the age of 50 whereas in India, it is above the age of $40^{2}$. In India the age standardized incidence rate of 
However, these benefits must be considered alongside potential harms, one being the overdiagnosis and overtreatment of screen-detected cancers that would otherwise never become apparent during the woman's lifetime..

Breast cancer is a highly heterogeneous disease that is developed by mutual impact of genetic risk factors and environmental factors. It leads to progressive aggregation of genetic and epigenetic changes in breast cancer cells. Although epidemiological evidence highlight the presence of risk factors (such as age, obesity, alcohol use, and exposure to estrogen in lifetime), family history of breast cancer is the strongest one. Almost $20 \%$ of all breast cancers have family origin, and etiologically are dependent to a specific predisposing gene of that disease 10. For a country like India with a huge population, diverse cultures, geographical variations, diets and habits, sources of information on cancer risk factors are considerably limited. The reasons for varying incidence of breast cancer among women are not fully understood, which are likely to be explained by reproductive and lifestyle factors such as Literacy, Diet, Age at menarche and menopause, Age at first delivery, Abortion, Family history of Breast Cancer 8,9.

\section{Need for the study}

An increasing trend in its incidence has been observed in most of the metro policies with Mumbai topping the list In India 80,000 new cases are detected every year. Diagnosis in early stages increases surveillance rate. The five-year survival rate is $90 \%$ in the $1^{\text {st }}$ stage, $75 \%$ in the second stage, $50 \%$ in the third stage and $<10 \%$ in the fourth 2 .
An urgent need in cancer control today is to develop effective and affordable approaches to the early detection, diagnosis and treatment of breast cancer among women living in less developed countries ${ }^{3}$.

Cancer facts revealed that the agestandardized incidence rate for breast cancer in India is 22.9 per 100,000 , onethird that of Western countries and the mortality rates are disproportionately higher. Breast cancer accounts for $22.2 \%$ of all new cancer diagnoses and $17.2 \%$ of all cancer deaths among women in India 5 . Breast cancer in urban areas of India is three times higher than in rural parts of the country. According to India statistics, the number of new breast cancer cases is about 115,000 per year and this is expected to rise to 250,000 new cases per year. If discovered early breast cancer can usually be cured; however, early detection through screening is the only way to reduce mortality. The most common screening for the early detection is breast selfexamination and mammogram. It has been shown that it reduced the breast cancer mortality by $30 \%$ in women aged 50 and older. A descriptive study done at Saudi, found that $56 \%$ women were unaware of these changes and some of them are reluctant to go for check-up due to many reasons such as; lack of knowledge, shyness, fears and delay in the treatment leads to complications and death ${ }^{10}$.

\section{Objective}

- To assess the prevalence of Breast cancer among high risk women in selected rural areas.

\section{Methodology}

- Descriptive research design was adopted for this study. The population of the study was Women whose age between $40-60$ yrs residing at seliyamedu village, Puducherry. 200 
samples were selected by non-probability convenient sampling technique based on inclusion criteria of Women between the age group of 40 yrs to $60 \mathrm{yrs}$ and available at the time of data collection with informed consent. The demographic variables were collected from the samples followed by breast examination was done to all the samples. The suspected high risk women had undergone mammogram to confirm the diagnosis of Breast cancer. The data were analyzed through descriptive statistics. The present study reveals that among 200 women, two women were diagnosed as breast cancer with the help of Mammogram -the confirmatory diagnostic measure.

Table 1 Prevalence Of Breast Cancer Among High Risk Women

\begin{tabular}{|c|c|c|c|}
\hline S.No & $\begin{array}{c}\text { Result of } \\
\text { Mammogram }\end{array}$ & Frequency & Percentage \\
\hline 1 & Positive & 2 & 1 \\
\hline 2 & Negative & 5 & 2.5 \\
\hline
\end{tabular}

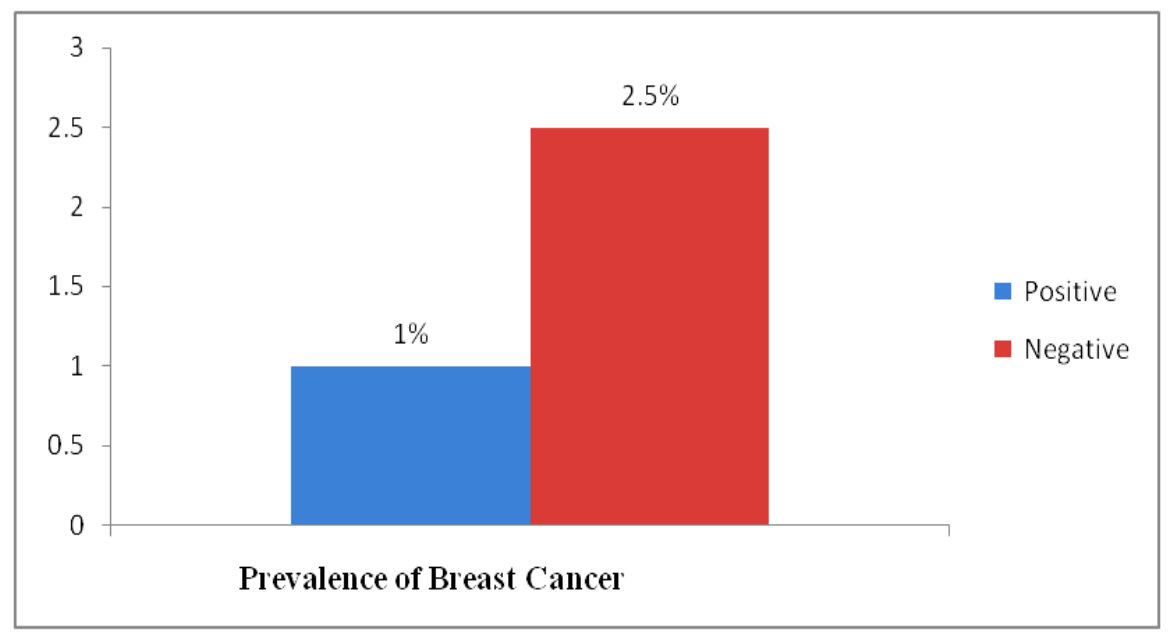

Out of 200 samples, 7 women were categorized as high risk for breast cancer. The Present study findings revealed that, out of 200 samples, 2 of them had diagnosed as Breast Cancer with the Result of Mammogram. Women who were diagnosed as Breast Cancer had risk factors of aging, dietary pattern, early Menarchae, early marriage, Family History of Cancer, Early Menopause.

\section{Results}

\section{Major findings}

- The above table depicts that among 200 women, 7 (3.5\%) had undergone mammogram. Out of 7 high risk women 1\% women between the age of 40-60 years , were diagnosed as Breast cancer by the confirmatory result of Mammogram.

- Out of 200 samples, 7 women categorized as high risk for breast cancer. The Present study findings revealed that, among 200 samples, 2 of them had positive Result For Breast Cancer . 
Women who were categorized as Breast Cancer they had risk factors of aging, dietary pattern, early Menarche, early marriage, Family History of Cancer, Early Menopause.

\section{Conclusion}

The study concluded that $2 \%$ of women diagnosed as breast cancer. The responsibility of the health care professional is to create awareness among the women regarding the risk factors, early diagnosis and management.

\section{References}

7. Hankey BF, Miller B, Curtis R et al. Trends in breast cancer in younger women in contrast to older women. J Natl Cancer InstMonogr 1994;16:714.

8. Population based cancer registries consolidated report (1990-96) [Last accessed on 2010 Oct 31]. Available from: http://www.icmr.nic.in/ncrp/ pbcr.pdf .

9. National cancer registry programme report (1981-2001) [Last accessed on 2011 Jan 24]. Available from http://www.icmr.nic.in/ncrp/c ancer regoverrview.htm.Jemal A, Bray F, Center MM, Ferlay J, Ward E, Forman D. Global cancer statistics. CA Cancer J Clin. 2011;61(2):69-90. doi: 10.3322/caac.20107.
1. Marcus PM, Newman B, Millikan RC, Moorman PG, Baird DD, Qaqish B. The associations of adolescent cigarette smoking, alcoholic beverage consumption, environmental tobacco smoke, and ionizing radiation with subsequent breast cancer risk. Cancer Causes Control. 2000;11(3):271-278.

2. Saki A, Hajizadeh E, Tehranian N. Evaluating the Risk Factors of Breast Cancer Using the Analysis of Tree Models.Ofogh-e-Danesh. Journal of Gonabad University of Medical Sciences. 2011;17(2):60-69.

3. Badwe RA, Gangawal S, Mittra I, Desai PB. Clinico-pathological features and prognosis of breast cancer in different religious communities in India. Indian J Cancer. 1990;27:220-8.

4. Development of an atlas of cancer in India. A Project of National Cancer Registry Programme supported by WHO 20012. [Last Accessed on 2011 Jan 24]. Available from: http://www.ncrpindia.org/Cancer Atlas Indaia/about.htm .

5. Meshram II, Hiwarkar PA, Kulkarni PN. Reproductive risk factors for breast cancer: A case control study. Online J Health Allied Sci. 2009;83:5.

6. Antoniou AC, Easton DF. Models of genetic susceptibility to breast cancer. Oncogene. 2006;25:5898.[PubMed]

\section{International Peer Review Members}

\section{Mr. Allan Seraj}

Senior Practice Educator in ICU RoyalBrompton\&Harefield Hospital NHS Trust, UK
Dr. Rachelle (Shelly) J. Lancaster Associate Professor of Nursing Oshkosh College of Nursing University of Wisconsin Oshkosh Wisconsin, USA. 